\title{
Vocabulary Instruction: Software Flashcards vs. Word Clouds
}

\author{
Vahid Mansouri \\ Payam Noor University of Guilan, Iran \\ E-mail: vmansouri66@gmail.com
}

Doi:10.7575/aiac.alls.v.6n.1p.41

URL: http://dx.doi.org/10.7575/aiac.alls.v.6n.1p.41
Received: 14/09/2014

Accepted: 16/11/2014

\begin{abstract}
When it comes to language learning, vocabulary learning is the main activity focused on. Vocabulary learning is the main problem and also the goal of new language learners. It is one of the major problems that language learners encounter during learning a new language. Krashen (1989) (cited in Tokac, 2005) points out the role of vocabulary in a language by stating that most of the meaning in a language is carried by words. This is why people visiting a foreign country prefer to take their dictionaries with them rather than grammar books. And on the other hand, nowadays everything is connected to technology and language learning and teaching is not an exception. As Stockwell (2007) cites, vocabulary has been one of the most commonly taught language areas through technology in recent years. Integration of computer and second/foreign language teaching is admired by many researchers. It is clear that technology can help enhance the degree of vocabulary learning, but the point is that which computer assisted vocabulary learning can work better and would be more efficient?

In this paper we will discuss and analyze the usage of two kinds of different ways of using technology and see which of the methods will work better. A comparison between vocabulary software flashcard and word clouds (Wordle) on vocabulary learning (retention) will be compared by the researcher. We will see that using which method will encourage learners more and they will do better with which kind of using technology? The study is carried out in Iran on 44 English learners. The result is really surprising. Both of the groups were interested in technology, but one group did really better.
\end{abstract}

Keywords: CALL, CAVL, Software flashcard, Word Clouds, Wordle, Vocabulary learning

\section{Introduction}

The importance of vocabulary learning is undeniable. The need for sustained vocabulary learning is clear. As August (2005) states, those English language learners who have a small range of vocabulary knowledge are less able to comprehend text and communicate. Allen also (1983) emphasizes the importance of vocabulary learning in ESL. He asserts that ESL teachers know thousands of words that speakers and writers of English use and also mentions "the need to vocabulary" as a point on which teachers and students agree! By stating that most of the meaning in a language is carried by words, Krashen (1989) points out the role of vocabulary in a language (cited in Tokac, 2005). This is why people visiting a foreign country prefer to take their dictionaries with them rather than grammar books. The importance of vocabulary learning in ESL/EFL classes is crystal clear. As cited in Eslahcar and Khodareza (2012) vocabulary learning is at the heart of language learning and language use. In fact, it is what makes the essence of a language (Laufer, 1997) . Zygadlo (2007) explains that it is impossible to conduct a message or communicate in English by those who may know some grammar, but their vocabulary knowledge needs to be enriched. He adds that those who have learned English as L2 for many years must have experienced that the majority of their time spent over the foreign language has been devoted to absorbing and remembering vocabulary. Gorjian, et al (2011) emphasize the importance of vocabulary learning by stating that students can improve their listening, speaking, reading and writing skills and may eventually improve comprehension and production in the L2 by vocabulary learning. Naiman, et al (1978), were interested in identifying many efficient techniques for language learning including: vocabulary, second acquisition, listening comprehension, grammar, speaking, writing and reading. Above the mentioned skills they found that focusing on vocabulary learning was the most important cited in Thu (2009).

Inability to make appropriate choice regarding what type of vocabulary learning strategy they should adopt in their learning process is one of the major problems that the majority of language learners encounter in initial stages of language learning (Baleghizadeh \& Ashoori, 2011).

\subsection{Importance of vocabulary learning}

The importance of vocabulary learning becomes more important when it comes to English learning. The reason is clear, English has a rich and a very large group of vocabularies. That's because English vocabulary is a complicated mixture of Germanic words and Romance words (Meara, 2005). Meara also states that the result of all this adoption of words is that English vocabulary presents a lot of very awkward problems for foreign learners. So there must be a good solution for this problem and it is necessary to familiarize learners with useful methods of vocabulary learning. If not, they may feel disappointed and lose their confidence (Nation, 2001). Teachers can also help learners choose efficient ways. 
According to Grabe and Stroller (2002), less priority is given to vocabulary learning in second language (L2) classrooms. Some other researchers (e.g. Hunt and Beglar, 2009; Folse, 2004) also agree that little research is carried out in this field (cited in Grabe \& Stroller, 2002). Hunt and Beglar (2005) state that second language vocabulary learning lacks the concentration on methods acquiring vocabulary. The importance of vocabulary learning is clear to all. Now the question is that: which method to use in order to teach vocabulary in the best way or which method would be the most efficient one in vocabulary acquisition?

\subsection{Different ways of vocabulary learning}

There were different discussions about the effect of explicit or implicit vocabulary learning. Coady (1993), Meara (1980 - 1984), Chall (1987) and some other researchers advocate implicit vocabulary learning while Bech, Mckewon and Osmonson (1983), Nation (2001), Paribakht, Wesche and Zimmerman (1997) were interested in explicit vocabulary learning.

Seal (1991) states that there are two types of vocabulary acquisition: planned and unplanned. In unplanned activities, learners ask for the meaning of words and the teacher's goal is to make the meaning clear. In planned activities on the other hand, teachers consider what and how to teach words.

Different ways of vocabulary learning and teaching were also proposed by different methods. From "Grammar Translation Method" that addressed vocabulary explicitly through introducing words in a list, to "Silent Method", "Direct Method" and to other methods and also Krashen (cited in Zimmerman, 1997) that believes in reading as the most effective way of acquiring new vocabulary (Zimmerman, 1997). In this paper, however, we are going to discuss about data visualization. Data visualization is a useful way of showing data. A picture is worth a thousand words, and of course it is very important to use a good way of data visualization. Oxford and Crokall (1990) (cited in Mahmoodi \& Talang, 2013) acknowledged the effects of visual aids and believed that using visual aids help most learners associate new information to concepts in memory and that that using visual aids (data visualization) learning can be more efficient.

\subsection{Vocabulary learning and technology}

On the other hand, nowadays, everything is connected to technology, and language learning and teaching is not an exception. As Stockwell (2007) cites, vocabulary has been one of the most commonly taught language areas through technology in recent years (e.g. Dodigovic, 2005; Yoshii, 2003; Yoshii \& Flaitz, 2002). Genc (2012) asserts that the rapid development and enormous advancement in computer technologies have been affecting all aspects of life for more than three decades. She also believes that the discipline of education is one of the most important areas that have been influenced by this huge improvement. According to the definition of English Wikipedia, Computer-assisted language learning (CALL) is an approach which focuses on using computer technology in learning or teaching a foreign language to students. Gorjian, et al (2011) state that language teaching has not remained inflexible towards the profound changes taking place in other areas of knowledge and advances in network technologies, connected with asynchronous CALL approaches, have resulted in the emergence of virtual worlds designed to facilitate synchronous (online) versus asynchronous (offline) communication among users (Gotjian, et al, 2011). We can use technology to help students and teachers learn and teach better and more effective. There is no doubt that technology can help enhance the quality of input, and the authenticity of resources, provide relevant and useful feedback, connect students with remote audiences, and train them in the use of technological advances that are fundamental skills in everyday life (Long \& Doughty, 2009). The impact of mixture of technology and education can be seen in classrooms as we can see computers, mp3 players, and also the access to the internet in many EFL/ESL classrooms. Computer-assisted language learning (CALL) is a wide field with different subfields including the use of internet, emails, applications, software, etc.

Integration of computer and second/foreign language teaching is admired by Chapelle (2005). in his article "computerassisted teaching and testing", he states that these changes in Teaching English as a Foreign Language (TEFL) and Teaching English as a Second Language (TESL) were promoted by computer technology in different subjects like: materials development, teaching methodology, classroom research, program evaluation, diffusion or innovation and teacher education. He also believes that technology can promote the complacent language educator to become a critical evaluator. Kern (2006), and Thorne and Payne (2005) mention that computer technology continues to increase in everyday utility among language learners as uses of communication devices such as blogs, wikis, and iPods which are cultural practices that students engage in outside of class (cited in Chapelle, 2005).

Zhao, et al (2004) state a common belief that technology is just a tool, a means to an end in education. They also add that the goal of educators using technology is to address the content of subject matter or some ability or qualities beyond the technology and not teaching their students how to use the technology.

\subsection{Word cloud and its different fields}

In a paper written by Al-Maamary, she suggests different ways of using word clouds in different levels and for different skills. Besides suggesting different ways for using word cloud for speaking, writing, and remedial classes, she also focuses on the importance and effects of using word clouds. Mentioning Gardner's theory of multiple intelligences, she puts word cloud under the category of spatial intelligence. She also considers using graphics and visuals inside the classroom as one implication of visual spatial intelligence. She states the fact that visuals are best-known sensory aids. She also suggests that new generation lives with technology, so we as English teachers, are supposed to align our teaching methods with technology. 
In a study done by Mahmoodi \& Talang (2013) they examined the effect of using word clouds on EFL students' longterm vocabulary retention. They did the research on 60 intermediate male and female students. The participants were divided into control and experimental group. The vocabularies were contextualized in six different texts for the control group. For the experimental group on the other hand, the participants were taught to use interactive web browser "wordsift" which could provide the subjects different objects including word clouds, concept maps, etc. finally the results showed that using wordsifts (word clouds) has significant effect on long-term vocabulary retention. The mean for the control group in the post-test was 23 while it was 29 for the experimental group.

\section{Methods}

\subsection{Participants}

Since using different technology related tools for vocabulary learning was the goal of this study, but not different ways of vocabulary teaching, there were no control/treatment grouping and both of the groups were treatment groups. As a result, the method used for vocabulary teaching for both of the groups was the same. The method used for vocabulary teaching was a normal method using examples, pictures, miming, etc. after teaching different vocabularies, different questions were asked to make sure that the students had gotten the meaning of words.

There were forty four participants in this study. The learners were all male (in both classes). Their native language was Farsi and they were studying English for 2 to 4 years (with a mean of 3). The range of their age was from sixteen to twenty-one (with a mean of 18.5). They were distributed into two classes of 23 and 21 . There was no educational or specific reason for the different number of students in the groups. The only reason that the 44 students are not equally divided into two 22 groups was the institute's policy not to have any class with even number of students..

One of the classes was chosen randomly to use word clouds (the class with twenty three students) and the other class (with twenty one students) was chosen to use software flashcards. The subjects had just finished the book Top Notch 1A and their new course book was Top Notch 1B (new series). So the book under treatment for this study was Top Notch 1B (J. Saslow, A. Ascher, Pearson Education, 2011). The classes were held 3 times a week on odd days and 90 minutes for each session. The duration of institute's term was 18 sessions which means the duration of the study was a month and a half.

\subsection{Materials}

To ensure homogeneity, a Michigan Test of English Language Proficiency (1997) was administrated at the beginning of the study to assess the participants' level of language proficiency. In this study, the first treatment group used word clouds to learn vocabularies being taught (WC group) and the other treatment group used software flashcards (SFC group).

\subsection{Procedure}

Two intact classes were used in this study and that is because of the effect of intact classes on increasing face validity of the research. One of the intact classes was chosen randomly to get word clouds (the class with nineteen students) and the other (the one with sixteen students) to get the software flashcards. Pretest was given to the students of the both groups consisting of 30 multiple choice items. The time for answering the test was 25 minutes.

At the end of the semester, post-test was given. Before administrating post-test, subjects in both classes read and agreed the consent form which had described the purpose of the study. Also, two versions of the same test were prepared to avoid cheating. In fact, the only difference between them was the different order of the questions and also items for each question.

Both groups received the same method for vocabulary teaching. The only difference was that in the WC group, a hard copy of the word cloud of the related text was given to the students and in the SFC group subjects received soft copy (power-point) of the software flashcard.

\subsection{Data analysis}

In this study there was one dependant variable (EFL learners' vocabulary learning) and two independent variables (vocabulary learning through software flashcard and vocabulary learning through word clouds).

In order to choose homogenous groups, the Michigan Test was administered to 65 students determining their proficiency level. Then, the students (44 out of 65) who performed about one standard deviation above and below the mean on the test were chosen as intermediate students. $T$ test was used to compare means of each group. To measure students' vocabulary learning, a 30-item test was given to the students.

\section{Results and analysis}

Statistics for treatment group WC are shown in table 3.1 and statistics for treatment group SFC are shown in table 3.2. Using and comparing both tables, we can understand the significant difference between two treatment groups (WC group and SFC group). As it is clear in the tables, the mean in WC group is 17.74 and in the SFC group is 15.62 
Table 3.1 Descriptive Statistics of vocabulary learning through using word clouds (WC group)

\begin{tabular}{ccccccccccc} 
N & Range & Min & Max & Sum & Mean & Variance & \multicolumn{2}{c}{ Skewness } & \multicolumn{2}{c}{ Kurtosis } \\
Stat. & Stat. & Stat. & Stat. & Stat. & Stat. & Stat. & Stat. & Std. & Statistic & Std. \\
& & & & & & & & & Error & Error \\
23 & 5 & 15 & 20 & 408 & 17.74 & 2.292 & .056 & .481 & -1.009 & .935 \\
23 & & & & & & & & & & \\
\end{tabular}

Table 3.2 Descriptive Statistics of vocabulary learning through using Software Flashcards (SFC group)

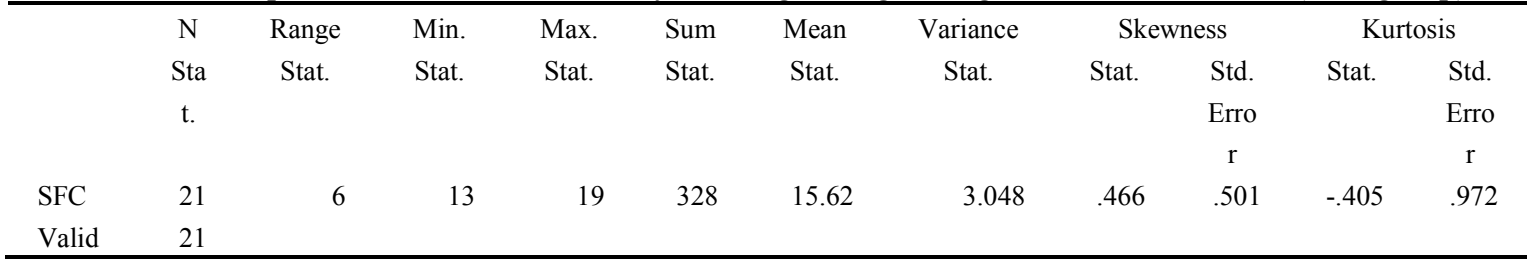

As it is shown in the tables, the mean in the WC group is higher than the mean in the SFC group.

Below we can also see the T-Test table that compares both groups' post test results. The mean for the treatment group $\mathrm{WC}$ is 17.74 .

Table 3.3 Group Statistics for both treatment groups

\begin{tabular}{llrrrr}
\multicolumn{6}{c}{ Table 3.3 Group Statistics for both treatment groups } \\
\hline \multirow{2}{*}{ VTscore } & Value & $\mathrm{N}$ & Mean & Std. Deviation & Std. Error Mean \\
& WC & 23 & 17.74 & 1.514 & .316 \\
& SFC & 21 & 15.62 & 1.746 & .381 \\
\hline
\end{tabular}

VT score in the table stands for Vocabulary Test score

Table 3.4 Independent Samples Test

\begin{tabular}{|c|c|c|c|c|c|c|c|c|c|c|}
\hline & & \multicolumn{2}{|c|}{$\begin{array}{c}\text { Levene's Test } \\
\text { for Equality of } \\
\text { Variances }\end{array}$} & \multicolumn{7}{|c|}{ t-test for Equality of Means } \\
\hline & & $\mathrm{F}$ & Sig. & $\mathrm{T}$ & Df & $\begin{array}{l}\text { Sig. } \\
(2- \\
\text { tailed })\end{array}$ & $\begin{array}{c}\text { Mean } \\
\text { Difference }\end{array}$ & $\begin{array}{l}\text { Std. } \\
\text { Error } \\
\text { Diffe } \\
\text { rence }\end{array}$ & $\begin{array}{r}95 \% \mathrm{C} \\
\text { Intery } \\
\text { Diff } \\
\text { Lower }\end{array}$ & $\begin{array}{l}\text { dence } \\
\text { the } \\
\text { ce } \\
\text { Upper }\end{array}$ \\
\hline VTscore & $\begin{array}{l}\text { Equal variances } \\
\text { assumed } \\
\text { Equal variances } \\
\text { not assumed }\end{array}$ & .347 & .559 & $\begin{array}{l}4.313 \\
4.285\end{array}$ & $\begin{array}{r}42 \\
39.828\end{array}$ & $\begin{array}{l}.000 \\
.000\end{array}$ & $\begin{array}{l}2.120 \\
2.120\end{array}$ & $\begin{array}{l}.492 \\
.495\end{array}$ & $\begin{array}{l}1.128 \\
1.120\end{array}$ & $\begin{array}{l}3.112 \\
3.120\end{array}$ \\
\hline
\end{tabular}

Table 3.4 shows the result of an independent $t$ test of vocabulary learning test between the post-test of both treatment groups. At a $95 \%$ confidence, $\mathrm{M}=2.120$, so it shows that the difference was statistically significant.

In the below graph, we can also see the range of difference in using word clouds and software flashcards in vocabulary learning.

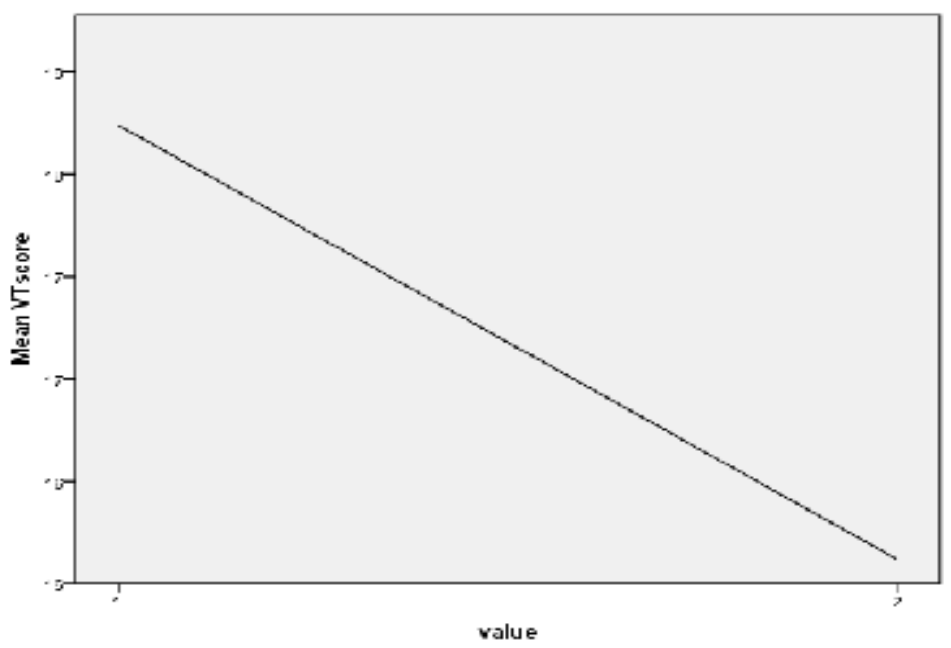

Figure 3.1 line graph

In the figure 3.1 value 1 stands for the WC group and value 2 stands for the SFC group. As the line indicates, the mean for the value 2 is higher. 


\section{Conclusion}

The first outcome is beside believing in technology, we need to know which way is the best and will help more. In this study as the data showed, the group with WC welcomed the way and got better results.

\subsection{Differences in VT score}

The participants' vocabulary learning in the WC group was improved via using word clouds as a tool for vocabulary learning and retention. The mean for this group was 2.120 higher than the mean for the treatment group SFC. Since each word cloud was for one text, it could be mentioned that there was cohesion among the words of each word cloud. So it could help students remember the words which they had forgotten the meaning by reading other related word. The significance difference in the SFC group also proves that although technology is helpful in most of the aspects of everyday life and especially learning, but every type of using technology cannot be that helpful.

\subsection{Implications and Recommendations for Teaching}

The most important implication is that as the technology develops, we also need to improve the ways of using technology. This study shows that using word clouds in vocabulary learning is significant.

The outcomes of this study suggest some pedagogical implication that could be taken into consideration by EFL designers, textbook writers, teachers, institute managers and so on. Although word clouds are not included in the text books yet, but teachers might use them as a helpful tool.

\subsection{Limitations and Delimitations}

Just male students have been participated in the research. The study has been done at Qanoon Language Center, so just the students of this institute were participated in the study.

Just two intact classes with the total number of 44 students (23 and 21) were the participants of this study. Covered materials in the study were based on an already designed curriculum of the institute.

Since Michigan Test was used to find homogenous students and there was no pre-test, it is possible that some students already knew some words in the final test (vocabulary test).

\subsection{Suggestions for Future Study}

This study compared using word clouds to software flashcards. Other researches may compare some more and different technology-based areas for learning.

This study was just conducted on male learners. Other studies may do research on female learners or even co-education classes. The present study was just done in one institute in Iran. To generalize the findings on EFL learners more classes with more numbers are needed.

\section{References}

Allen, V. (1983). Techniques in Teaching Vocabulary. New York: Oxford.

Al-Maamary, F. (n.d.) Using word clouds, The More Frequent, the Bigger. Sultan Qaboos University

Baleghizadeh, S. and Ashoori, A. (2011). The impact of two instructional techniques on EFL learners' vocabulary knowledge: flash cards versus word lists. MEXTESOL Journal, 35; 2, 1-9

Cahpelle, C. (1998). Multimedia CALL: lessons to be learned from research on instructed SLA. Language Learning \& Technology, 2; 1, 21-39.

Eslahcar, M. \& Khodareza, M. (2012). The effect of using vocabulary flashcard on Iranian pre-university students' vocabulary knowledge. International Education Studies, 5; 3, 134-147.

Gorjian, B. Moosavinia, R. Ebrahimi, K. Asgari, P. Hydarei, A. (2011). The impact of Asynchronous computer-assisted language learning approaches on English as a Foreign Language high and low achievers' vocabulary retention and recall. Computer Assisted Language Learning, 24; 5, 383-391.

Hunt, A., \& Beglar, D. (2005). A framework for developing EFL reading vocabulary. Reading in foreign language, 17, 23-59.

Mahmoodi, M., \& Talang, T. (2013). The Effect of Using Word Clouds on EFL Students' Long-Term Vocabulary Retention. Journal of English Language Teaching and Learning, 74-106

Meara, P. (2005). English vocabulary. Pearson education.

Seal, B. (1991). Vocabulary learning and teaching. In M. Celce-Murcia (Ed.) Teaching English as a Second or Foreign Language (296-311). Boston, MA: Heinle \& Heinle Publishers.

Stockwell, G. (2007). Vocabulary on the Move: Investigating an intelligent mobile phone-based vocabulary tutor. Computer Assisted Language Learning, 20; 4, 365-383.

Thu, T. H. (2009). Learning strategies used by successful language learners. Online Submission.

Tokac, A. (2005). A Comparison of Computer-Assisted Vocabulary Instruction and Teacher-led Vocabulary Instruction. The Institute of Economics and Social Sciences of Bilkent University.

Zhao, Y. Torres, M. Smith, B. Tan, H. (2004). The NON-NEUTRALITY of Technology: A Theoretical Analysis and Empirical Study of Computer Mediated Communication Technologies. J. Educational Computer Research, 30; 1\&2, $23-55$

Zimmerman, C. B. (1997). Historical trends in second language vocabulary instruction. New York, Cambridge University Press. 